NBER WORKING PAPER SERIES

\title{
MEDICAID POLICY CHANGES IN MENTAL HEALTH CARE AND THEIR EFFECT ON MENTAL HEALTH OUTCOMES
}

\author{
Alison Cuellar \\ Sara Markowitz \\ Working Paper 12232 \\ http://www.nber.org/papers/w12232
NATIONAL BUREAU OF ECONOMIC RESEARCH
1050 Massachusetts Avenue
Cambridge, MA 02138
May 2006

Funding for this work was provided in part by a research grant from the National Institute of Mental Health, K01 MH067086-01 (PI Cuellar). We would like to thank Sandy Decker, Marisa Domino, Don Kenkel, David Marcotte, and participants at the American Economic Association meeting, the Sheps Center for Health Services Research, and iHEA for helpful suggestions. We also thank Deepa Danan, Austin Henkel, Elizabeth Oo, and Daniel Yu for excellent research assistance. The views expressed herein are those of the author(s) and do not necessarily reflect the views of the National Bureau of Economic Research.

(C)2006 by Alison Cuellar and Sara Markowitz. All rights reserved. Short sections of text, not to exceed two paragraphs, may be quoted without explicit permission provided that full credit, including $\odot$ notice, is given to the source. 
Medicaid Policy Changes in Mental Health Care and Their Effect on Mental Health Outcomes Alison Cuellar and Sara Markowitz

NBER Working Paper No. 12232

May 2006

JEL No. I0

\begin{abstract}
In recent years, Medicaid has experienced a dramatic increase in spending on prescription drugs in general and psychotropic medications in particular. The purpose of this study is to examine the effects of increased Medicaid spending on psychotropic drugs on improving the mental health and well-being of participants at the population level. Specifically, we study the effect on outcomes that are strongly correlated with mood disorders, including depression, and Attention Deficit/Hyperactivity disorder, controlling for concomitant increases in Medicaid eligibility thresholds and expansion into managed care for mental health services. Knowledge of the effects of changes in the Medicaid program is crucial to policymakers as they consider implementing and expanding mental health services. Our results show that increased spending on antidepressants and stimulants are associated with improvements in some outcomes, but not in others.
\end{abstract}

Alison Cuellar

Department of Health Policy \& Management

Mailman School of Public Health

Columbia University

600 West $168^{\text {th }}$ Street, $6^{\text {th }}$ Floor

New York, NY 10032

ac2068@columbia.edu

Sara Markowitz

Rutgers University

Department of Economics

360 Dr. Martin Luther King Jr. Blvd.

Newark, NJ 07102

and NBER

smarkow@rutgers.edu 


\section{INTRODUCTION}

In recent years, Medicaid has experienced a dramatic increase in spending on prescription drugs in general and psychotropic medications in particular. From 1991 to 2001, Medicaid spending on all prescription drugs increased from $\$ 4.7$ billion to $\$ 24.1$ billion (18.6 billion in 1991 dollars), while spending on psychotropic drugs increased from $\$ 0.6$ billion to $\$ 6.7$ billion (5.2 billion in 1991 dollars) during the same time period. ${ }^{1}$ In other words, the share of total pharmaceutical spending represented by psychotropic drugs increased from 12.8 percent to 28 percent in 10 years. Knowledge of the effects of changes in the Medicaid program are crucial to policymakers as they consider implementing and expanding mental health services. At issue is whether expansions in treatment at the margin have improved health outcomes.

This spending by the Medicaid program has been of particular policy concern, as total spending for Medicaid has outpaced national health spending by more than tripling since 1990 (CMS 2000, US Census Bureau 2005). As part of their proposals to reduce overall Medicaid spending, several policy bodies, including the Bipartisan Medicaid Commission established by the Secretary of the U.S. Department of Health and Human Services, have recommended giving states the flexibility to limit pharmaceutical spending through higher co-payments to recipients (USDHHS, 2005). ${ }^{2}$ The Medicaid Commission estimates that this proposal will save $\$ 2$ billion over 5 years.

The increase in Medicaid spending for psychotropic drugs results from several federal and state policy changes including coverage for new, more effective drugs, expansions of

\footnotetext{
${ }^{1}$ Authors' tabulations using Medicaid drug rebate program provided by the Centers for Medicare and Medicaid Services.

${ }^{2}$ Currently, federal statute limits the amount of co-payments that can be charged, in most cases to $\$ 3$ for prescription drugs. Certain categories of beneficiaries, such as children under 18, pregnant women, and the institutionalized cannot be charged co-payments.
} 
Medicaid and SCHIP insurance coverage, particularly for youth, and the implementation of managed care for mental health services.

The introduction of new drugs has affected all payers, but Medicaid in particular, because a disproportionate fraction of Medicaid beneficiaries are treated for mental health disorders. Low income children, for example, are 2 to 3 times more likely to have a serious mental disorder than other children (Glied et al. 1997). New mental health drugs include new agents and new drug forms that are easier to administer, have simpler dosing schemes, reduce the likelihood of overdose or abuse, and offer fewer negative side effects (USDHHS 1999; Frank et al. 2005). All of this means that it is easier for clinicians to design mental health treatment regimens and easier for patients to adhere to them. These newer drugs also have higher drug prices, due to their patent protections and lack of competition from generic drugs. At the same time, managed care incentives favor the use of prescription drugs over other therapies, while expanded Medicaid eligibility further increased spending.

The growth in pharmaceutical spending has encouraged Medicaid programs and its managed care arrangements to implement cost control measures, some of which may severely restrict access to psychotropic drugs. Restrictions include caps on the number of different prescriptions that can be filed at one time, prior approval for more expensive drugs or for an entire class of drugs, mandatory substitution of generics, and exclusions of drugs from formularies (Semansky and Koyanagi 1999). As Medicaid programs continue to struggle to meet rising program costs, further scrutiny of prescription drug spending is likely (Coughlin and Zuckermann 2005). States need to be aware of the consequences of limiting access to medications, and our research helps to highlight some of the benefits of these drugs. 
As states assess their psychotropic medication budgets, can a case be made that increased spending for psychotropic medication has measurably improved mental health outcomes?

Obviously, drugs are approved for safety and efficacy by the U.S. Food and Drug Administration and clinical studies further support their use. However, these studies tend to be short-term, based on small samples, and reflect a tightly controlled treatment environment. They also do not typically compare newer drugs to their older alternatives. Ultimately, the effectiveness of these drugs in usual care settings is less well understood, making appropriate policy more difficult to identify.

The primary purpose of this study, therefore, is to examine whether or not Medicaid psychotropic drug spending has contributed to improvements in health and well-being, as measured by a variety of outcomes that are strongly correlated with mental illnesses. When analyzing this question, it is important to account for several other changes in the Medicaid program that occurred during the 1990s and that had dramatic effects on the provision and receipt of care for beneficiaries. New program eligibility rules and shifts from fee-for-service to managed care arrangements may have increased access to health services other than prescription drugs, and may have had an independent effect on improved outcomes. Evaluating the impact of Medicaid psychotropic drug spending on outcomes requires us to separate the effects of psychotropic drugs spending from other Medicaid policies that may have contributed to greater mental health services utilization or quality.

This study provides evidence regarding three Medicaid policies that all changed during the 1990s: greater access to psychotropic drugs, increases in eligibility thresholds, and expansion into managed care for mental health services. We examine the impact of these policies on suicides, violent crimes, property crimes, and fatalities resulting from unintentional 
injuries. These outcomes were chosen because of their strong association with certain types of mental health problems. Our results show that increased spending on antidepressants and stimulants are associated with improvements in some outcomes, but not in others.

\section{BACKGROUND}

In this paper, we examine two types of the most common classes of psychotropic drugs, antidepressants and stimulants. In recent years, Medicaid expenditures for these psychotropic drug categories have increased dramatically. Real spending for Medicaid antidepressants rose from $\$ 137$ million to $\$ 1.2$ billion nationally from 1991 to 2001, while stimulant spending rose from $\$ 12$ million in 1991 to $\$ 158$ million in $2001 .^{3}$ Innovations in several psychotropic drug classes are partly responsible for increased Medicaid spending. Other factors that have exerted upward pressure on Medicaid include expanded insurance coverage, direct-to-consumer advertising, and managed care benefit designs (Frank et al. 2005).

Antidepressants. Antidepressants are used in the treatment of mood and anxiety disorders. The 12 month prevalence of these disorders in adults is 18.1 percent for anxiety and 9.5 percent for mood (Kessler, Chiu et al. 2005). The lifetime prevalence of these disorders in adults is much higher at 28.8 percent for anxiety and 20.8 percent for mood (Kessler, Berglund et al. 2005). Since 1987 some important changes have taken place in the development of antidepressants, including the introduction of selective serotonin reuptake inhibitors (SSRIs). Compared to earlier antidepressants, such as tricyclic antidepressants (TCAs) and monoamine oxidase inhibitors (MAOIs), SSRIs are easier to administer, reduce the likelihood of overdose, and offer fewer negative side effects (USDHHS, 1999). The late 1990s ushered in another set of new medications, including selective norepinephrine and serotonin reuptake inhibitors (SNRIs),

\footnotetext{
${ }^{3}$ All medication spending figures are adjusted by the U.S. city average consumer price index for prescription drugs and medical supplies.
} 
as well as chemically unrelated antidepressants. Within Medicaid the expansion of new antidepressants in dollars and in number of prescriptions is remarkable (Figure 1). Over ten years, the number of Medicaid prescriptions per enrollee for new depression drugs rose 14-fold from 0.04 to 0.67 prescriptions per enrollee, while real spending rose 14 -fold from $\$ 2.80$ to \$39.19 per enrollee. Real spending on older antidepressants dropped by 10 percent, while the number of prescriptions per enrollee remained virtually unchanged. These trends are similar for both children and adults (see Figure 2).

Stimulants. Stimulants, which are used in the treatment of Attention Deficit/Hyperactivity Disorder (ADHD) and other conduct disorders, are another type of drug that has become more widely used in the past decade. ${ }^{4}$ The increase is due, in part, to changes in the preparation of the drugs which allows for a sustained and extended release formulas that offer flexible dosing options, increase compliance, and lead to greater continuity of treatment (Marcus et al. 2005). From 1991 to 2001 real spending per enrollee increased almost 9-fold, while number of prescriptions increased 6-fold (Figure 3).

Stimulants are primarily used by children. ${ }^{5}$ ADHD has a lifetime diagnosed prevalence of 9.7 percent in children ages 9-17 (Visser, and Lesesne 2005) and an estimated 4.1 percent of youths ages 9 to 17 in a 6-month period (Shaffer et al. 1996). People with ADHD have difficulty sitting still and concentrating. They also are more impulsive than others. These characteristics may make them more prone to accidents, injuries, and also to initiating fights with others (DiScala et al. 1998; Barkley 2004).

Medicaid Eligibility Expansions. Increases in the volume of drugs used by Medicaid

\footnotetext{
${ }^{4}$ Using data from the 2002 National Drug and Therapeutic Index (NDTI), we calculate that Attention Deficit Disorder, Conduct Disorder, and not otherwise specified Overactivity Disorders account for 92 of the conditions for which stimulants are prescribed.

${ }^{5}$ In 2001, children ages 5 to 18 accounted for 76 percent of all physician visits with stimulant drug appearances. [Authors' tabulations of NDTI data.]
} 
patients has been partly driven by Medicaid eligibility expansions. In 1997, Congress created the State Children's Health Insurance Program (SCHIP). Since then almost every state raised the income eligibility threshold for children, increasing both the number eligible and the number enrolled (Morreale and English, 2003). Changes in Medicaid and the addition of SCHIP programs have resulted in a tremendous expansion of the number of eligible individuals, particularly children. These expansions, in turn, have contributed to increases in psychotropic drug spending. Furthermore, they may have had an independent positive effect on outcomes through access to treatment other than drug therapies.

As the Medicaid program has changed and expanded over time, researchers have studied the effects of these changes on eligibility, take up rates, health utilization, and physical health outcomes. Children and pregnant women have been the primary focus of much of this research, but the effects on mental health outcomes are less well-known. Studies have shown that the Medicaid expansions contributed directly to the improved physical health of children as measured by increased office visits, decreased ambulatory care sensitive hospitalizations, reduced episodes of illnesses, and reduced functional limitations (Currie and Gruber 1996; Kaestner et al. 2001; Lykens and Jargowsky 2002). One goal of our study is to contribute to the literature regarding the effects of Medicaid expansions on several outcomes related to mental health.

Medicaid Managed Care. States have sought to contain Medicaid costs through greater use of managed care style insurance coverage, particularly for mental health care services. Nationally, enrollment in Medicaid managed care (MMC) plans that cover mental health services increased from under 10,000 to almost 8 million from 1991 to $2001{ }^{6}$ Figure 4 shows the proportion of Medicaid enrollees in managed care plans for mental health services over time,

\footnotetext{
${ }^{6}$ Authors' tabulations from the National Summary of State Medicaid Managed Care Programs.
} 
which rose from less than one percent in 1991 to 38 percent in 2001.

Attributes of mental health managed care contracts have contributed to increased pharmaceutical spending in Medicaid. Medicaid contracts for mental health services can come in a variety of forms, including risk-based, capitated payments to health plans that cover both physical and mental health care and risk-based, carve-out contracts with specialized health plans that cover mental health services only (Holahan et al. 1999). Under carve-out plans, mental health insurance coverage is financially and administratively separated from physical health coverage. Although Medicaid behavioral carve-out plans cover specialty mental health services, they typically are not at risk for pharmacy services (Findley, 1999; Frank, Huskamp, Pincus, 2003). When behavioral carve-outs are not at risk for pharmaceutical spending, this creates incentives to encourage greater use of drugs instead of psychotherapies. Among privately insured individuals, for example, Berndt et al. (1997) found that depressed patients in managed care plans were more likely to be treated with antidepressants than depressed patients in fee-forservice plans. Such treatment substitution is controversial in part because of controversies over effective treatment practices. One particular area of controversy is in the use of antidepressants for children. This is discussed in greater detail below.

Aside from creating incentives to increase pharmaceutical spending, managed care may have direct effects on mental health services utilization and outcomes. Managed care has been demonstrated to reduce the cost of mental health treatment services by reducing unnecessary hospitalizations and promoting cost-effective care (USDHHS 1999). However, the efficacy of managed care in increasing the use of mental health services is still in question (Goldman et al. 1998; Leslie et al. 2001).

Studies evaluating the effect of Medicaid managed care on health outcomes are scarce. 
Kaestner et al. (2005) examine the effects of managed care arrangements on prenatal care use, birth outcomes and incidences of cesarean sections. The authors find no firm evidence that MMC causes any significant differences in these outcomes as compared to that of traditional Medicaid. A few other studies show that MMC is associated with a reduction in avoidable hospitalizations among children (Gavin et al. 1998, Godomski et al. 1998).

\section{Previous Population-based Studies}

The major policy question relevant for this paper is what Medicaid is getting for its money. In other words, is the increased spending on psychotropic medications having a noticeable effect on the quality of people's lives? Clinical studies, even those based on randomization designs, can provide only a partial answer. Randomized control studies typically suffer from small sample sizes, sample selection issues, limited scope, and limited geographical relevance. Frequently, the treatment is studied under highly controlled, "ideal" circumstances, rather than under circumstances that typify usual medical practice. Survey data, even national in scope, frequently have insufficient samples for the study of relatively rare health outcomes. As a result, population-based data reflecting actual care patterns are desirable. Duggan (2005), for example, uses statewide Medicaid claims data from California to analyze the effects of increased spending on second-generation antipsychotics on health outcomes among Medicaid schizophrenia patients. He finds no effects on hospitalizations, but finds suggestive evidence that these drugs reduce the prevalence of side effects, while increasing the fraction of patients with diabetes.

In a population-based study using Medicaid claims data, Croghan et al. (1998) examine whether the type of antidepressant predicts treatment adherence and depression relapse. Their results are suggestive and indicate, at least indirectly, that if SSRIs improve length of therapy 
they also improve adherence and relapse outcomes.

\section{METHODS}

We take a different approach to measuring health outcomes for persons with mental illness and focus on a number of population-based outcomes that are strongly linked with depressive disorders and conduct disorders. These outcomes include suicides, unintentional injuries, and crime. Our rationale for choosing these outcomes is discussed in detail below. Since depressive disorders and conduct disorders are commonly treated with antidepressants and stimulants, respectively, it seems reasonable to relate changes in spending or prescriptions for these drugs with outcomes related to the illnesses.

\section{Outcomes}

Suicide. Suicide serves as a good proxy for mental health status since suicide is strongly correlated with depression and other mental illnesses. Researchers believe that almost all individuals who commit suicide have a diagnosable mental disorder (Maris 1992). Depression is the single most common mental disorder associated with suicide among youth (Brent et al. 1988). It has been estimated that two-thirds of people who commit suicide have a depressive illness; 5 percent suffer from schizophrenia; and 10 percent meet the criteria for other mental illnesses including borderline personality disorder (Maris 1992, Maltsberger1992).

When increased spending on antidepressants reduces the length and severity of depression and related disorders and prevents suicides, the public health benefits of increased spending on antidepressants are obvious. However, while the new antidepressants are safe and effective for treating adults with depression, there is growing concern about the risks of prescribing antidepressants to children. Recent reports link the use of antidepressant drugs to an increased risk of suicidal behaviors in children and teenagers. The Food and Drug 
Administration (FDA) recently directed manufacturers of antidepressant drugs to change their labels to include a warning about the increased risk of suicidal thinking and behavior in children and adolescents (FDA, 2004). For adults, special health professional and patient information sheets warn about the risks of suicide in SSRIs, SNRIs, and other newer antidepressants. ${ }^{7}$

The link between increased spending on antidepressants and suicide among children and adults is likely to be highly debated in the academic literature. There is no consensus in the existing literature, with some studies finding no relationship (Barbui et al. 1998; Jick et al. 2004; Valuck et al. 2004), another finding a positive relationship (Dahlberg and Lundin 2004), others finding a negative relationship (Carlsten et al. 2001; Olfson et al. 2003; Hall et al. 2003; Isacsson 2000; Ludwig and Marcotte 2005), and yet one other finds negative and positive relationships depending on whether newer or older antidepressants classes are analyzed (Gibbons et al. 2005).

Unintentional Injuries: Research has shown that the characteristics of ADHD make sufferers more prone to accidents, injuries, and also to initiating fights with others (DiScala et al. 1998; Barkley 2004). The treatment of ADHD with stimulants has been found to improve some of these outcomes (Cox et al. 2004). A large scale clinical trial found that treatment of ADHD with stimulants, behavioral therapies, or a combination of both, helped children control their activity level and impulsiveness, pay attention, and focus on tasks over the 14 month follow-up period (MTA Cooperative Group 1999). Other short-term studies support the efficacy of stimulants and also of psychosocial treatments for ADHD in children (NIH 2000).

Individuals with ADHD may be at higher risk for injury than others because of their lack of concentration or their inability to develop safety strategies in dangerous situations (Discala et

\footnotetext{
${ }^{7}$ Antidepressants that have health professional and patient information sheets regarding suicide risks include Wellbutrin (bupropion), Celexa (Citalopram), Cymbalta (duloxetine), Effexor (venlafaxine), Lexapro (escitalopram), Fluvoxamine, Paxil (paroxetine), Prozac (fluoxetine), Remeron (mirtazapine), Serzone (nefazodone), and Zoloft (sertraline). See http://www.fda.gov/cder/drug/antidepressants/antidepressantList.htm accessed August 252005.
} 
al. 1998). Empirically, findings on a variety of unintentional injuries and ADHD are mixed. Faigel et al. (1995) find that untreated ADHD results in increased injuries, traffic citations, bone fractures, and head injuries. Similarly, Discala et al (1998) find that among children with trauma injuries those with ADHD were more likely to be injured as pedestrians and to inflict injury on themselves, and their injuries were more likely to be severe. Others found no relationship between ADHD and pedestrian injury (Christoffel et al. 1996).

Crime. A sense of hopelessness and lack of future orientation may cause persons with depression to discount future consequences and be more likely to commit crimes. A study of adults in treatment for serious mental illness found a one-year prevalence of assaultive behavior of 13 percent; furthermore, those with mood disorders reported higher rates of violent acts than those with psychotic disorders (Swanson et al. 2002). Co-occurring substance abuse disorder has also been found to play an important role in the relationship between violence and mental disorder (Steadman et al. 1998). Another study of jail inmates found higher rates of mental illness, including major depression, than community samples (Teplin, 1990). However, a study of former adult jail detainees finds that the risk of being re-arrested for a violent crime was no greater for those with depression than those with no mental disorder, although this study does not address possible reverse causation (Teplin et al. 1994).

Juveniles are more apt to act out their depression through disruptive and aggressive behaviors than adults (Bleiberg, 1991). Problems with social functioning and peer relations can make juveniles with depression more prone to delinquent behavior and aggression (Brimaher, et al, 1998). Youth with ADHD also are at greater risk for crime and arrest than similar populations without the disorder (Satterfield and Schell 1997; Barkley et al. 2004). Youth with ADHD, for example, experience peer rejection and engage in numerous disruptive behaviors 
(NIH 2000); their increased impulsivity also has been found to lead to greater initiation of fights (Halperin et al. 1995).

Suicides, violent crimes, property crimes, and fatalities resulting from unintentional injuries are chosen as outcomes because of their strong associations with depression and ADHD. We recognize that many other factors are likely to be associated with rates of these outcomes, particularly crime and unintentional injuries. However, these outcomes are studied because they are plausibly influenced by the receipt of mental health care. In the absence of direct, individual outcomes of mental health, these outcomes represent the best available population based measures.

\section{Data}

The number of completed suicides in each state for individuals of all ages is our first dependent variable. We also examine suicides for youth ages 10 to 19 separately from adults 20 and over. These data come from the National Center for Health Statistics' Compressed Mortality File. Second, we use data from the FBI Uniform Crime Report to measure criminal offenses and arrests. We use state-level violent and property offenses (i.e. crimes reported to the police) which represent crimes committed by offenders of all ages. Separately, we examine juvenile arrest rates for violent and property crimes. Lastly, fatal unintentional injury data for ages 5-18 are used which come from the Centers for Disease Control's Web-based Injury Statistics Query and Reporting System (WISQARS). These data are collected from death certificates. We examine the effects of the Medicaid variables first on all types of unintentional injuries, and then separately on three common injuries: drowning, falls, and burns. The category of unintentional injuries includes a wide variety of causes of injury including fire, firearms, machine, poisoning, and transportation related accidents. 
One caveat that is important to highlight is that all of our outcome measures are population based. This means that we observe outcomes of individuals who are covered by Medicaid as well as those who are not covered. This may bias our results towards zero; however, as we lack health outcomes specific to the Medicaid population, population based measures seem to be a reasonable alternative. We discuss the implications of this further below.

\section{Medicaid Variables}

Medicaid Eligibility Rate. Our measure of Medicaid eligibility expansions is the annual proportion of all children who are eligible for Medicaid or SCHIP based on state-specific thresholds. State Medicaid and SCHIP income eligibility thresholds for children were provided by the National Governors Association.

Medicaid SAMH Managed Care Enrollment Rate: This is the number of people enrolled in Medicaid managed care plans offering mental health services divided by the total number of nonelderly Medicaid enrollees. Enrollment numbers come from The National Summary of State Medicaid Managed Care Programs. This is an annual publication available from the Centers for Medicare and Medicaid Services (CMS) of the U.S. Department of Health and Human Services. Descriptions of each state's Medicaid managed care programs are collected from state Medicaid agencies and CMS Regional offices. Details on the services covered and the populations enrolled by the managed care plans are included in the summaries. The descriptions include the number enrolled in managed care, but unfortunately this data is not available by age group.

Therefore, enrollment for all age groups is used in all models. Managed care plans are expected to lower the cost of providing mental health services to the Medicaid population; therefore we expect states to offer increased access to care and lower injury rates and crime rates where enrollments are higher. 
Medicaid Pharmaceuticals: Pharmaceutical use is measured by real spending on antidepressants or stimulants per enrollee. We also test models that include alternatively the per enrollee number of Medicaid prescriptions for these drugs. These data come from the Centers for Medicare and Medicaid Services and refer to spending and prescriptions for all enrollees of all ages. The state drug utilization data are gathered by the federal government to track the cost of drugs in each state's Medicaid program and to monitor implementation of the Medicaid drug rebate program. ${ }^{8}$ The data include outpatient drugs by National Drug Code (NDC) purchased by year and state. The NDC code identifies the drug manufacturer, drug product, and package size. From the list of NDC codes we identify stimulants and newer and older antidepressants. ${ }^{9}$ Approximately 570 manufacturers submit product data to the federal government. The data include the total prescriptions reimbursed and total Medicaid reimbursements made by the state for each drug. The year is based on date of payment, not date of service. However, beginning in 1994 states began to incur penalties for late or incomplete data.

\section{Empirical Model}

We expect that policies which expand access to mental health treatment will improve mental health and improve related outcomes among Medicaid populations. We use a panel of outcomes measured at the state-level for 1991-2001 as these years represent the available years for the Medicaid data.

The general model uses a state-level outcome as the dependent variable in a multivariate regression. Given that all outcomes are counts, we use the Fixed Effects Poisson (FEP) estimator to estimate the models (Wooldridge 2002; Cameron and Trivedi 1998). This estimator is a quasi-maximum likelihood estimator that includes parameters or "fixed effects" to account

\footnotetext{
${ }^{8}$ Data for Arizona and Tennessee are not included because of non-reporting.

${ }^{9}$ We thank Haiden Huskamp for providing us a list of antidepressant NDC codes which was created in consultation with clinician experts.
} 
for unobserved heterogeneity across the units of observation (states, in our case). Estimates are consistent regardless of whether the counts actually have a Poisson distribution (Wooldridge 2002). To permit overdispersion, a common feature of count data that is not accommodated by the Poisson MLE, standard errors are adjusted for heteroskedasticity of unknown form (Cameron and Trivedi 2005). Each model includes the log of the relevant population as a right hand side variable to normalize for exposure. The coefficient on log population is constrained to equal one. When the resulting coefficients are small $(b<.01)$, as in the case with most of our results, the coefficients can be interpreted directly as semi-elasticities. That is, these coefficients represent the percentage change in the dependent variable resulting from a one unit change in the independent variable.

All models included the Medicaid eligibility threshold, the Medicaid managed care enrollment rate, and a measure of pharmaceutical spending. When suicide is considered the models include spending on depression drugs per Medicaid enrollee. Spending is divided into the categories of spending on "new" drugs, which include all SSRIs and SNRIs and "old" drugs, which includes MAOIs and TCAs. For fatal unintentional injuries, the measure of pharmaceutical spending is dollars spent on stimulants per Medicaid enrollee. Since crime is strongly related to many different types of mental illnesses we consider spending on antidepressants and spending on stimulants in alternative models. Note that in models which consider stimulate spending, we restrict the outcomes to juveniles when possible since most stimulants are prescribed to children. The correlation between old and new antidepressant spending and number of prescriptions is relatively low ( 0.17 and 0.47 , respectively). The correlation between spending on new antidepressants and stimulants is very high $(\mathrm{r}=.76)$ so models that include both types of drugs suffer from the problems of multicollinearity. 
To control for observable state differences likely to affect outcome rates, all models contain state-level variables measuring demographic and socio-economic status. Descriptive statistics are presented in Table 1. These variables include the unemployment rate, the female labor force participation rate, real income per capita, and the percentage of the population living in rural areas. We add state and year fixed effects to capture permanent state heterogeneity in outcome rates and national trends that may coincide with Medicaid policy changes. Lastly, state*trend interactions are included to capture annual state-specific trends that may coincide with Medicaid changes.

Despite inclusion of numerous Medicaid policy and other control variables, spending on psychotropic medication may be highly correlated with other omitted Medicaid program characteristics, such as the state's overall generosity in Medicaid. These in turn may affect outcomes which would lead to biased estimates of the mental health drug effects. To address this issue we conduct a counterfactual analysis and examine the relationship between drugs that we would not expect to have an effect on the mental health outcomes. We chose cholesterollowering drugs, which also expanded greatly over this time period, as our counterfactual example. ${ }^{10}$ All models were rerun using Medicaid spending and prescriptions for cholesterollowering drugs. Figure 5 shows increases in Medicaid spending and prescriptions per enrollee for cholesterol-lowering drugs. From 1991 to 2001 real spending and number of prescriptions increased almost 6-fold.

\section{RESULTS}

The first hypothesis we test is that increased spending on antidepressant will lower suicides. Multivariate analysis of suicide by age group are presented in Table 2. Here, the effect

\footnotetext{
${ }^{10}$ Several statins were approved including lovastatin (Mevacor) in 1988, pravastatin (Pravachol) in 1991, simvastatin (Zocor) in 1991, atorvastatin (Lipitor) -- a statin more potent per milligram than other statins -- in 1996, fluvastatin (Lescol) in 1993, an extended release version of Lescol in 2000.
} 
of antidepressant spending varies by drug class. Among people of all ages, spending on newer depression drugs is associated with an increase in suicides, while spending on older depression drugs is associated with a decrease in suicides. However, the spending results appear to be driven by differences in age groups. Columns 2 and 3 show the effects of the Medicaid variables on suicides of those ages 10-19 (column 2) and 20 and up (column 3). We break the suicides into these age groupings to test the recent FDA findings that antidepressants may increase suicidal behaviors among youth. We caution that these results are only suggestive as we are making inferences from matching spending for all ages with age-specific suicides.

Our results are partially consistent with the FDA concerns. We find that increased spending on newer drugs is associated with an increase in suicides for youth. The magnitude of the effect is fairly large, with a one dollar increase in per enrollee spending leading to a 0.5 percent increase in youth suicides. However, spending on older antidepressants appears to have a negative, although imprecisely estimated effect on youth suicides. Here, a one dollar increase in spending leads to a 1.4 percent decrease in youth suicides. We also find that increase spending on older depression drugs lowers suicides among adults while spending on new depression drugs has no effect. A one dollar increase in per enrollee spending on old drugs leads to a 1.1 percent decrease in adult suicides.

With regard to other Medicaid policies, we find that across all ages increases in managed care penetration has no effect on suicides. However, expanded Medicaid eligibility lowers suicides for youth. Because the eligibility expansions were primarily targeted at children and youth, it is not surprising that expanded eligibility had no significant effect for adults.

We ran similar suicide models using cholesterol-lowering drugs rather than antidepressants as a test of our results (column 4). In these models we expect to find no effect of 
drug spending on suicides. The results confirm our hypothesis, implying that the measure of antidepressant spending likely is not biased by unobservables such as Medicaid program generosity.

Next we examine the effects of Medicaid spending on antidepressants on violent and property offenses (Table 3). Columns 1 and 2 show that per enrollee spending on older antidepressants also lowers violent and property offenses. The decline in offenses is small, 1.4 percent for violent crimes and 1.0 percent for property crimes. No similar effect was found for newer antidepressants, eligibility thresholds or managed care. To check our results, we reran these regressions substituting in spending for cholesterol-lowering drugs (results available upon request). The coefficients on cholesterol-lowering drugs are not statistically significant, as hypothesized. Next we examine the effect of stimulant spending on violent and property offenses. Columns 3 and 4 show that stimulant spending lowered offenses of both types, but the effect is small, less than one percent.

Our offenses measures combine offenses committed by children and adults. Because stimulants are primarily used by youth, we examined youth arrests for violent and property crimes separately. Columns 5 and 6 show no effect of stimulant spending. Further, eligibility expansions appear to have very small, positive effects on youth arrests.

In Table 4 we examine the effect of stimulant spending on unintentional injuries among children. Per enrollee stimulant spending has no significant impact on fatal injuries of all types. For all injuries, falls, and fires, the coefficients on stimulant spending are negative as expected, but are not statistically significant at conventional levels. This result may not be surprising given the nature of and commonality of unintentional injuries annually (national annual totals ranging from 7000-8000 for children ages 5-18 as compared to 1400 suicides among the same age 
group). Many of these injuries may simply be accidents and unrelated to ADHD or other mental illness.

We tested all models measuring drugs as numbers of prescriptions per Medicaid enrollee rather than as real spending per enrollee and the results are qualitatively similar. Table 5 shows only the coefficients for the key Medicaid policy variables across the outcomes. The models control for the same independent variables as before, but these coefficients are not shown. Using number of prescriptions rather than spending per enrollee confirms the previous suicide results. Per enrollee prescriptions for newer antidepressants are associated with higher youth suicide rates and results are statistically significant. Older antidepressants are associated with fewer adult suicides. Further, Medicaid eligibility expansions are associated with declines in suicide for youth, but not for adults, which is plausible given that eligibility expansions primarily targeted younger ages.

Results, however, differ somewhat for the crime models. Using the prescription rather than spending measure we find that the coefficients on antidepressants in the offense models remain negative, but become statistically insignificant. Panel B of Table 5 shows that stimulants are associated with declines in violent offenses, but not property offenses or youth arrests.

Lastly, Panel C of Table 5 shows that results with the per enrollee number of prescriptions measure are similar to that of expenditures for unintentional injuries. Here we find no effect of stimulants across several types of unintentional injury.

\section{DISCUSSION}

In an era of dramatic increases in spending on psychotropic medicines, this paper asks the questions, what does Medicaid get for its money, and does the increased spending improve the lives of beneficiaries. We examine the influence of Medicaid medication spending and 
prescriptions on the mental health of enrollees as measured by rates of suicide, criminal offenses and arrests, and fatal unintentional injuries.

Our results show that increased spending on antidepressants influences suicides. For adults, we find support that increased spending on "old" antidepressants (tricyclics and monoamine oxidase inhibitors) are associated with reductions in suicides for adults, while increased spending on "new" drugs such as SSRIs has no effects for adults. In terms of the policy debates around antidepressants for youth, we find partial support for FDA concerns. Although the black label warning applies to all types of antidepressants, we only find an increased effect on youth suicide from greater spending on newer types of antidepressants. In contrast, spending on older antidepressants is associated with a negative, but imprecisely estimated effect on youth suicide. We caution that this analysis can not fully address the question of which antidepressant drug type is preferable for youth. Effects on other important youth outcomes such as school performance and family functioning are not addressed here. Furthermore, in considering these results, it is important to remember that the drug measures used here refer to spending and prescriptions for enrollees of all ages, not just youth. We provide partial evidence that drug use patterns among youth mimic those of adults. If the patterns are similar with only the levels differing, the results presented here will hold. In future research we will attempt to address this issue.

Results for the expansion of stimulants are encouraging when violent crime is considered. Negative and statistically significant effects were found for stimulants when violent offenses are considered. The evidence for property crimes is suggestive, but not conclusive as results for prescriptions vary widely from that of spending. Based on a national figure of approximately 17,500,000 reported violent offenses over the 1991-2001 period, a 0.8 percent reduction in 
violent offenses per dollar spent per enrollee on stimulants translates into approximately 140,000 violent crimes averted over the 11 years. The reduction in property crimes would be 483,000 over the 11 years.

Separately, we identified the effect of two other major Medicaid policies. To the best of our knowledge, this paper is the first to evaluate the effect of Medicaid mental health managed care on related outcomes. Managed care has statistically insignificant effects in all but two of our models. The exceptions apply to property offenses and burns, with higher enrollment rates increasing property offenses and falls. The managed care coefficients should be interpreted as the effects on health outcomes after controlling for the impact of managed care on psychotropic drug spending. Because mental health managed care is likely to increase spending on psychotropic drugs, we are essentially measuring the impact of other characteristics of these arrangements, such as possibly reduced access to psychotherapies. Given the overall lack of effects of managed care, our results should help to alleviate concerns about detrimental financial incentives within these programs.

In terms of the effect of Medicaid eligibility expansions that is not mediated through prescription drug access, we find that these expansions lower youth suicides, raise youth arrests, and youth unintentional injuries. It is unclear why expansions should raise arrests and unintentional injuries. This question should be addressed in future research.

Although provocative, our results are subject to limitations. One limitation is that we cannot measure whether medication use is targeted at those with the most severe mental conditions or the greatest possible benefit. In addition, there is some degree of mismatch between the age of individuals represented by the health outcome and the age applicable to the Medicaid variables. Specifically, we relate youth suicides to managed care enrollment and 
depression drug spending for people of all ages. Ideally, we would like to conduct this analysis with age-specific data, however, to the best of our knowledge this data is not available.

Another potential limitation is that the outcome variables include behaviors by individuals who are not eligible for Medicaid, thus potentially biasing the results towards zero. However, in 2001, 18 percent of children ages 10 to 19 were enrolled in Medicaid and 42 percent met Medicaid and SCHIP income eligibility criteria. ${ }^{11}$ In addition, low income children are 2 to 3 times more likely to have a serious mental disorder than other children (Glied et al. 1997). Since we find statistically meaningful and non-trivial results, particularly for suicides, we believe that this bias is not severe. The true effects may be much larger than we estimate.

It also is possible that our measure of Medicaid spending for antidepressants and stimulants is acting as a proxy for aggregate spending for antidepressant and stimulants across all payers, to the extent that the Medicaid trends mirror those in the population as a whole. The factors that caused increases in both Medicaid utilization of drugs and in prices for new and existing drugs - managed care, advertising, and innovation - may also apply to private insurance. However, the trends would have to be similar both in times series and cross sectionally across states. We are unable to assess these patterns in this study.

This research is the first step in evaluating the influence that changes in the Medicaid program may have on the mental health status of enrollees. The spending results may also provide lessons for other insurers providing prescription drug benefits. For example, this research is relevant to Medicare as it prepares to provide its prescription drug benefit. Recent guidance to Medicare prescription drug plans under Part D requires coverage of "all or substantially all" medications in the classes of anti-psychotics, antidepressants and anticonvulsants (CMS, 2005). Further, the ability to restrict utilization through tools such as prior

\footnotetext{
${ }^{11}$ Authors' tabulation of the Current Population Survey.
} 
authorization or step therapy, are limited. Even though our results are not generalizable to the elderly population, our research demonstrates some of the potential benefits that may be realized by increased spending on psychotropic medicines. 


\section{References}

Barbui C. A Campomori, B. D’Avanzo E. Negri and S. Garattini. Antidepressants drug use in Italy since the introduction of SSRIs: national trends regional differences and impact on suicide rates", Social psychiatry and psychiatric epidemiology, 1999, 34, 152-156.

Barkley RA, Murphy KR, Kwasnik D. Motor Vehicle Driving Competencies and Risks in Teems and Young Adults with Attention Deficit Hyperactivity Disorder. Pediatrics, 1993, 98:1089-1095.

Barkley, Russell A; Fischer, Mariellen; Smallish, Lori; Fletcher, Kenneth. Young adult follow-up of hyperactive children: antisocial activities and drug use. Journal of Child Psychology \& Psychiatry. Vol 45(2) Feb 2004, 195-211

Berndt E, Frank RG, and McGuire TG. "Alternate Insurance Arrangements and the Treatment of Depression: What are the Facts?" American Journal of Managed Care, 3(2):243252, 1997.

Bleiberg E, "Mood Disorders in Children and Adolescents." Bulletin of the Menniger Clinic 1991, 55:182-204.

Brent DA, Perper JA, Goldstein CE, et al "Risk Factors for Adolescent Suicide: A Comparison of Suicide Victims with Suicidal Inpatients," Archives of General Psychiatry 1988, 45: 581-587

Brimaher B, Brent DA, and Benson RS: Summary of the Practice Parameters for the Assessment and Treatment of Children and Adolescents with Depressive Disorders. Journal of the American Academy of Child and Adolescent Psychiatry 1998, 37:1234-1238.

Cameron, CA and PK Trivedi. Microeconometrics Methods and Applications. New York: Cambridge University Press, 2005.

Carlsten A, M Waern, A Ekedahl and J Ranstam. Antidepressant medication and suicide in Sweden. Pharmacoepidemiology and drug safety, 2001, 10: 525-530.

Centers for Medicare and Medicaid Services (CMS), "Medicare Modernization Act Final Guidelines - Formularies" accessed http://www.cms.hhs.gov/pdps/specguidncmaterials.asp

Centers for Medicare and Medicaid Services (CMS), A Profile of Medicaid: Chartbook 2000. U.S. Department of Health and Human Services, Washington DC, 2000.

Christoffel KK, Donovan M. Schofer J, Wills K, Lavigne JV and the Kids 'n Cars Team. Psychosocial Factors in Childhood Pedestrian Injury: A Matched Case-Control Study. Pediatrics. 1996, 97:33-42.

Coughlin TA and Zuckermann S, Three Years Of State Fiscal Struggles: How Did Medicaid And SCHIP Fare? Health Affairs Web Exclusive, August 16, 2005

Cox, DJ, Merkel, RL, enberthy, JK, Kovatchev, B, Hankin CS. Impact of methylphenidate delivery profiles on driving performance of adolescents with attention deficit/hyperactivity disorder: A pilot study. J. Am Acad Child Adolesc Psychiatry 2004. 43(3):269-275

Croghan, TW, C A Mefli, WE Crown, and A. Chawla. 1998. Cost Effectiveness of Anti-depressant Medications. Journal of Mental Health Policy and Economics 1: 109-117.

Croghan, TW, BM Johnstone, D Buesching, RC Kessler. 1999. Information Needs for Medication Coverage Decisions in a State Medicaid Program. Medical Care. 37(4): AS24AS31.

Cuellar, AE, S Markowitz, AM Libby, "Mental Health and Substance Abuse Treatment and Juvenile Crime" Journal of Mental Health Policy and Economics, 2004 June; 7 (2): 59-68 
Currie J and Gruber J, "Saving Babies: The Efficacy and Cost of Recent Expansions of Medicaid Eligibility for Pregnant Women," The Journal of Political Economy, 1996: 104:12631296.

Dahlberg M and Lundin D, “Antidepressants and the Suicide Rate: Is There Really a Connection? Working Paper. Uppsala University, 2004.

DiScala, C, Leschohier I, Barthel, M, Guohua L. Injuries to Children with Attention Deficit Hyperactivity Disorder. Pediatrics. 1998, 102(6): 1415-1421.

Duggan M, "Do New Prescription Drugs Pay for Themselves? The case of secondgeneration Antipsychotics," Journal of Health Economics 2005, 24:1-31

Faigel, H.C., Sznajderman, S., Tishby, O., Turel, M., \& Pinus, U. Attention Deficit Disorder during adolescence: A review. Journal of Adolescent Health, 1995, 16, 174-184.

FDA, Public Health Advisory: Suicidality in Children and Adolescents Being Treated With Antidepressant Medications, issued 10/15/2004, http://www.fda.gov/cder/drug/antidepressants/SSRIPHA200410.htm

Findlay S: Managed behavioral health care in 1999: an industry at a crossroads. Health Affairs 18(5):116-124, 1999

Frank R, Huskamp H, Pincus H. Aligning incentives in the treatment of depression in primary care with evidence-based practice. Psychiatr Serv. 2003;54:682-687.

Frank RG, Conti RM, Goldman HH, 'Mental Health Policy and Psychotropic Drugs,' Milbank Quarterly 2005, 83:271-298

Gadomski, Anne, Paul Jenkins, and Melissa Nichols. Impact of a Medicaid Primary Care Provider and Preventive Care on Pediatric Hospitalization. Pediatrics, Mar 1998; 101: e1.

Gavin, Norma I. Ferrelly, Matthew C; Simpson Jr, Joe B. Children's use of primary and preventive care under Medicaid managed care. Health Care Financing Review. 1998 Summer 19: 4 45-68.

Gibbons RD, K Hur, DK Bhaumik, and JJ Mann. 2005. The Relationship Between Antidepressant Medication Use and Rate of Suicide. Archives of General Psychiatry. 62:165172

Glied, Sherry, R. Moore, C. Hoven, A.B. Garrett, D. Regier. “Children's Access to Mental Health Care: Does Insurance Matter?” Health Affairs, 16(1) 1997: 167-174.

Goldman, W. McCulloch, J and Sturm, R. (1998). Costs and use of mental health services before and after managed care. Health Affairs, 17, 40-52.

Hall WD, A Mant, PB Mitchell, VA Rendle, IB Hickie, Peter McManus. Association Between Antidepressant Prescribing and Suicide in Australia, 1991-2000: Trend Analysis. British Medical Journal, 10 May 2003, 326.

Halperin JM, Newcorn JH, Matier K, Bedi G, Hall S, Sharma V. Impulsivity and the Initiation of Fights in Children with Disruptive Behavior Disorders. Journal of Child Psychology, Psychiatry, and Allied Disciplines. 1995; 36: 1199-1211.

Holahan, J; S. Rangarajan; M Schirmer. "Medicaid Managed Care Payment Rates in 1998." Health Affairs 1999 May-Jun;18(3):217-27.

IMS Health. National Disease and Therapeutic Index, 1997-2002.

Isacsson, G. Suicide prevention-a medical breakthrough? Acta Psychiatrica Scandinavica, 2000, 102: 113-117.

Jick, H, JA Kaye and SS Jick. Antidepressants and the Risk of Suicidal Behaviors. JAMA, July 21, 2004, 292:3, 338-343. 
Kaestner, Robert, Theodore Joyce and Andrew Racine. "Medicaid Eligibility and the Incidence of Ambulatory Care Sensitive Hospitalizations for Children." Social Science and Medicine 2001, 52, 305-313.

Kaestner, R, L Dubay and J Kenney. "Managed care and infant health: an evaluation of Medicaid in the U.S." Social Science \& Medicine, 60:8, April 2005, 1815-1833.

Kessler, RC, Chui WT, Demler O, Walters EE, Prevalence, Severity, and Comorbidity of 12-Month DSM-IV Disorders in the National Comorbidity Survey Replication, Arch Gen Psychiatry. 2005;62:617-627.

Kessler, RC; P Berglund; O Demler; R Jin; KR Merikangas; EE Walters. "Lifetime Prevalence and Age-of-Onset Distributions of DSM-IV Disorders in the National Comorbidity Survey Replication." Arch Gen Psychiatry. 2005;62:593-602.

Leslie, DL, RA Rosenheck, SM Horwitz. "Patterns of mental health utilization and costs among children in a privately insured population." Health Serv Res. 2001 Apr;36(1 Pt 1):113-27.

Lykens KA and PA Jargowsky. Medicaid matters: Children's health and Medicaid eligibility expansions. Journal of Policy Analysis and Management. 21:2, 2002. 219-238.

Ludwig, Jens and Marcotte, Dave E. 2005. Anti-depressants, suicide and drug regulation. Journal of Policy Analysis and Management. 24(2): 249-272.

Marcus SC, GJ Wan, JE Kenner, M Olfson. 2005 Continuity of Methylphenidate Treatment for Attention-Deficit/Hyperactivity Disorder. Archives of Pediatric and Adolescent Medicine. 159:571-578.

Maltsberger, JT "The Psychodynamic Formulation: An Aid in Assessing Suicide Risk" in Maris RW, Berman AL, Maltsberger JT, and Yufit, RI (Eds) Assessment and Prediction of Suicide, New York: The Guilford Press. 1992.

Marris, RW. "Overview of the Study of Suicide Assessment and Prediction" in Maris RW, Berman AL, Maltsberger JT, and Yufit RI (eds). Assessment and Prediction of Suicide, The Guilford Press: New York, 1992.

Morreale, MC and A English. Eligibility and enrollment of adolescents in Medicaid and SCHIP: recent progress, current challenges. Journal of Adolescent Health. 32:6, s1, June 2003. 25-39.

The MTA Cooperative Group. A 14-month randomized clinical trial of treatment strategies for attention-deficit/hyperactivity disorder. Multimodal treatment study of children with ADHD. Archives of General Psychiatry, 1999; 56(12): 1073-86.

National Institutes of Health. Consensus development conference statement. Diagnosis and treatment of attention-deficit/hyperactivity disorder (ADHD). Journal of the American Academy of Child and Adolescent Psychiatry, 2000; 39(2): 182-93.

National Institute of Mental Health. Attention Deficit Hyperactivity Disorder. Bethesda, MD: Author, 2003. http://www.nimh.nih.gov/publicat/adhd.cfm\#adult. [accessed June 2005]

Olfson M; Shaffer D; Marcus SC; Greenberg T. "Relationship between antidepressant medication treatment and suicide in adolescents." Archives of General Psychiatry, 60(10): 97882,2003

Satterfield, James H.; Schell, Anne. A Prospective Study of Hyperactive Boys With Conduct Problems and Normal Boys: Adolescent and Adult Criminality. Journal of the American Academy of Child \& Adolescent Psychiatry. 36(12):1726-1735, December 1997.

Semansky, Rafael M. and Koyanagi, Chris . Medicaid Formulary Policies: Access to High-Cost Mental Health Medications Bazelon Center, November 1999. 
Shaffer D, Fisher P, Dulcan MK, et al. The NIMH Diagnostic Interview Schedule for Children Version 2.3 (DISC-2.3): description, acceptability, prevalence rates, and performance in the MECA Study. Methods for the Epidemiology of Child and Adolescent Mental Disorders Study. Journal of the American Academy of Child and Adolescent Psychiatry, 1996; 35(7): 86577.

Steadman, et al Archives of General Psychiatry, 1998

Swanson, JW, Swartz MS, Essock, SM, et al The social-environmental context of violent behavior in persons treated for severe mental illness. American Journal of Public Health, 2002, 9 (2): 1523-1531.

Teplin LA, The Prevalence of Severe Mental Disorder Among Male Urban Jail Detainees: Comparison with the Epidemiologic Catchment Area Program. American Journal of Public Health 1990, 80 (6), 663-673

Teplin, Linda A.; Abram, Karen M.; McClelland, Gary M. "Does psychiatric disorder predict violent crime among released jail detainees? A six-year longitudinal study". American Psychologist. 49(4), Apr 1994, 335-342.

Tsuang MT, Borr, M, Fleming JA. Psychiatric Aspects of Traffic Accidents. American Journal of Psychiatry. 1985; 142:538-546.

U.S. Census Bureau. Statistical Abstract of the United States, 2004-2005. Washington, DC.

U.S. Department of Health and Human Services. Mental Health: A Report of the Surgeon General-Executive Summary. Rockville, MD: U.S. Department of Health and Human Services, Substance Abuse and Mental Health Services Administration, Center for Mental Health Services, National Institutes of Health, National Institute of Mental Health, 1999.

U.S. Department of Health and Human Services. The Medicaid Commission. September 1, 2005 accessed at http://www.cms.hhs.gov/faca/mc/090105rpt.pdf.

Valuck, RJ, AM Libby, MR Sills, AA Giese and RR Allen. Antidepressant treatment and risk of suicide attempt by adolescents with major depressive disorder. CNS Drugs, 2004, 18(15): 1119-1132.

Visser, SN and CA Lesesne. "Mental Health in the United States: Prevalence of Diagnosis and Medication Treatment for Attention-Deficit/Hyperactivity Disorder --- United States, 2003. MMRW, September 2, 2005 / 54(34);842-847.

Wooldridge, Jeffrey M., Econometric Analysis of Cross Section and Panel Data, Cambridge, MA: MIT Press, 2002. 
Figure 1

Antidepressants Spending and Prescriptions

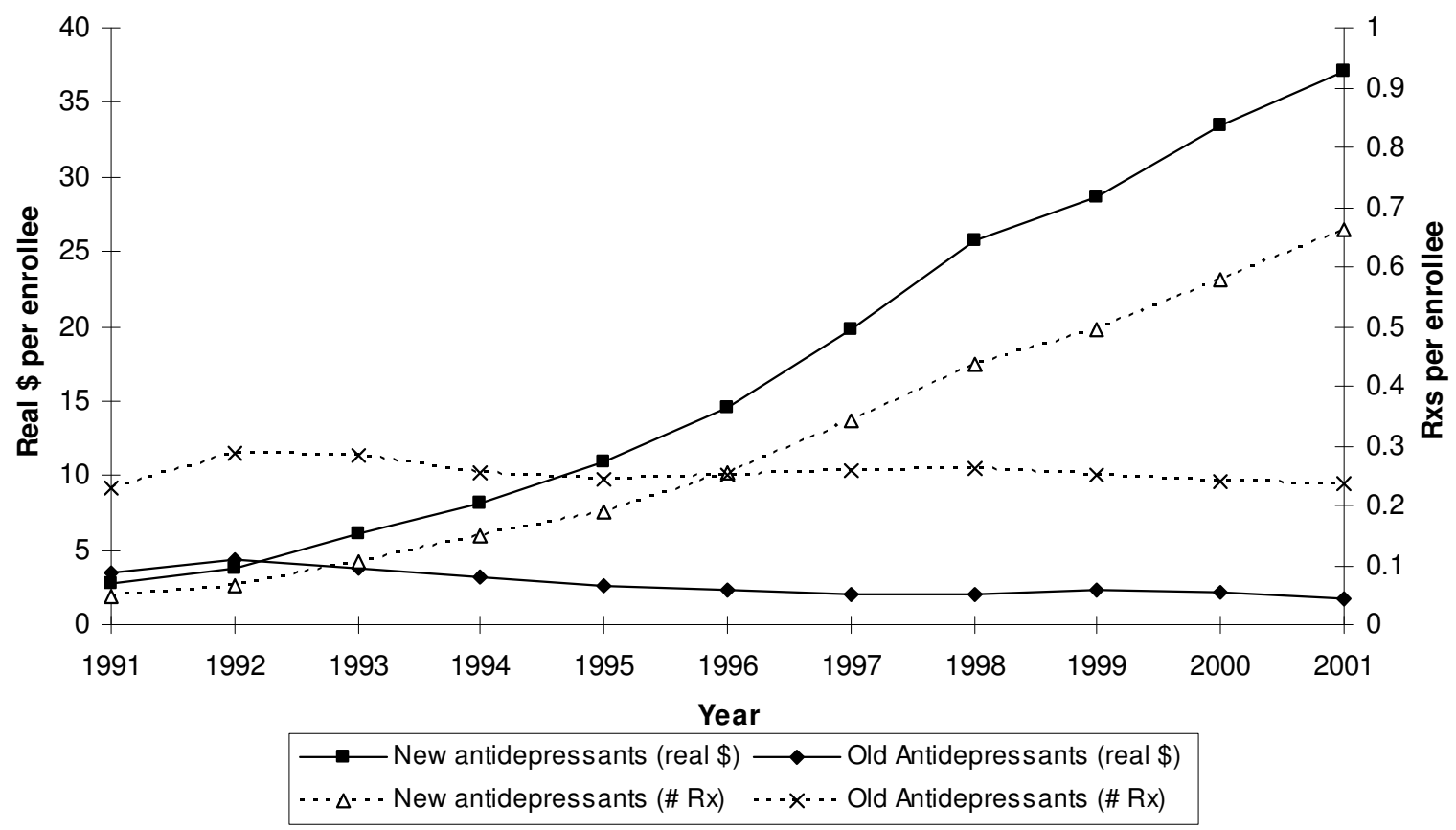

Source: CMS Medicaid Drug Rebate Program

Figure 2

Antidepressant Prescriptions by Age

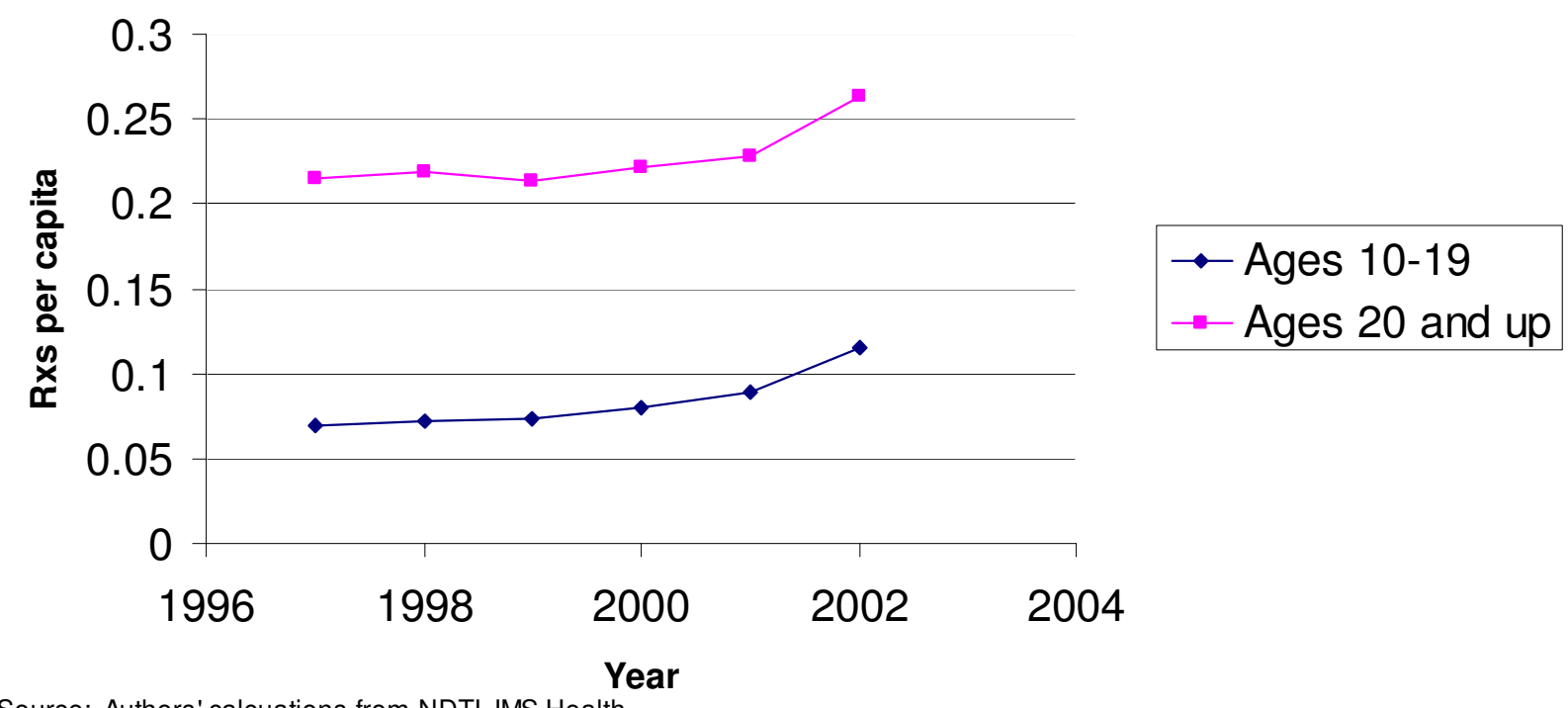

Source: Authors' calcuations from NDTI, IMS Health 
Figure 3

Stimulant Spending and Prescriptions

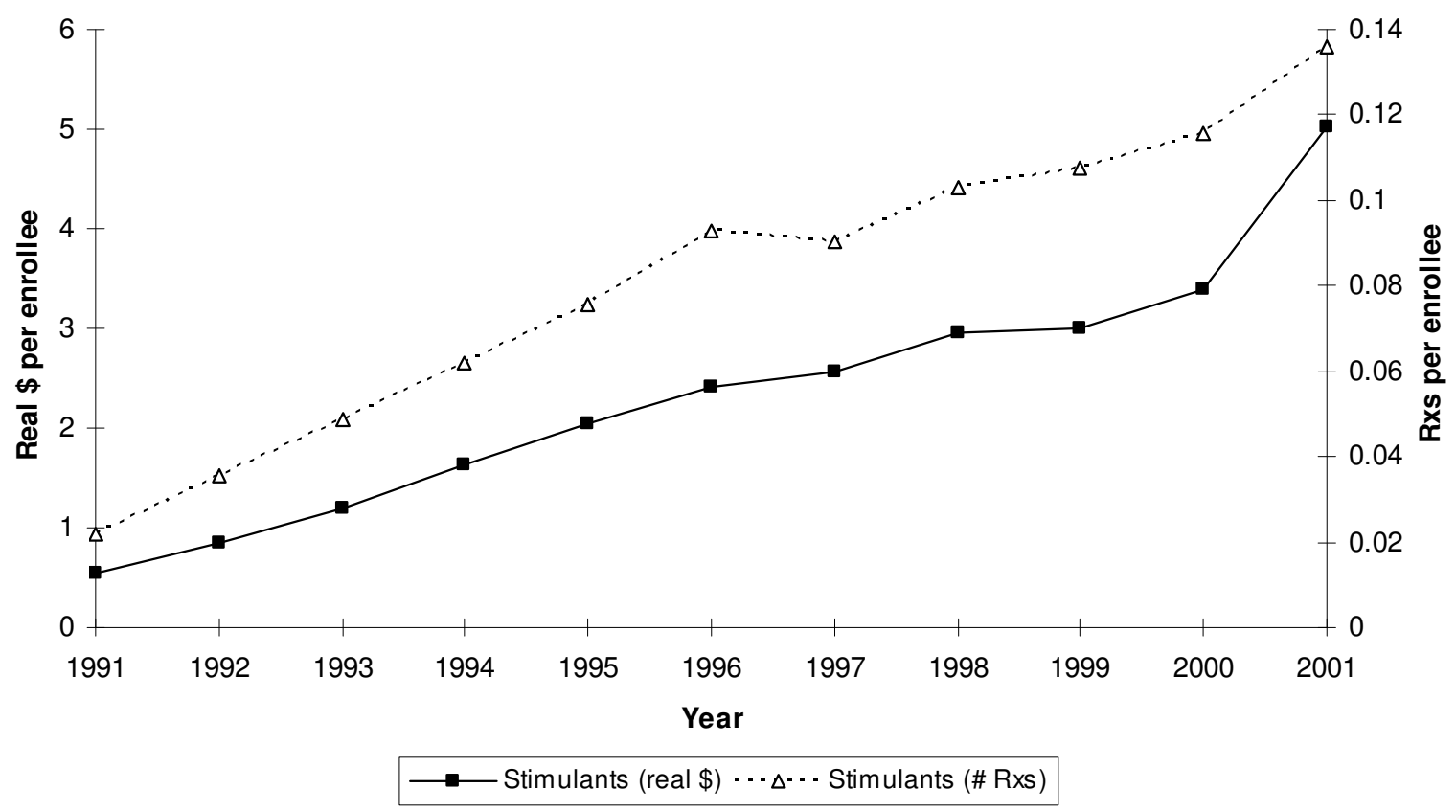

Source: CMS Medicaid Drug Rebate Program

Figure 4

National Percentage of Medicaid Enrollees Under 65

in Subtance Abuse/Mental Health Managed Care

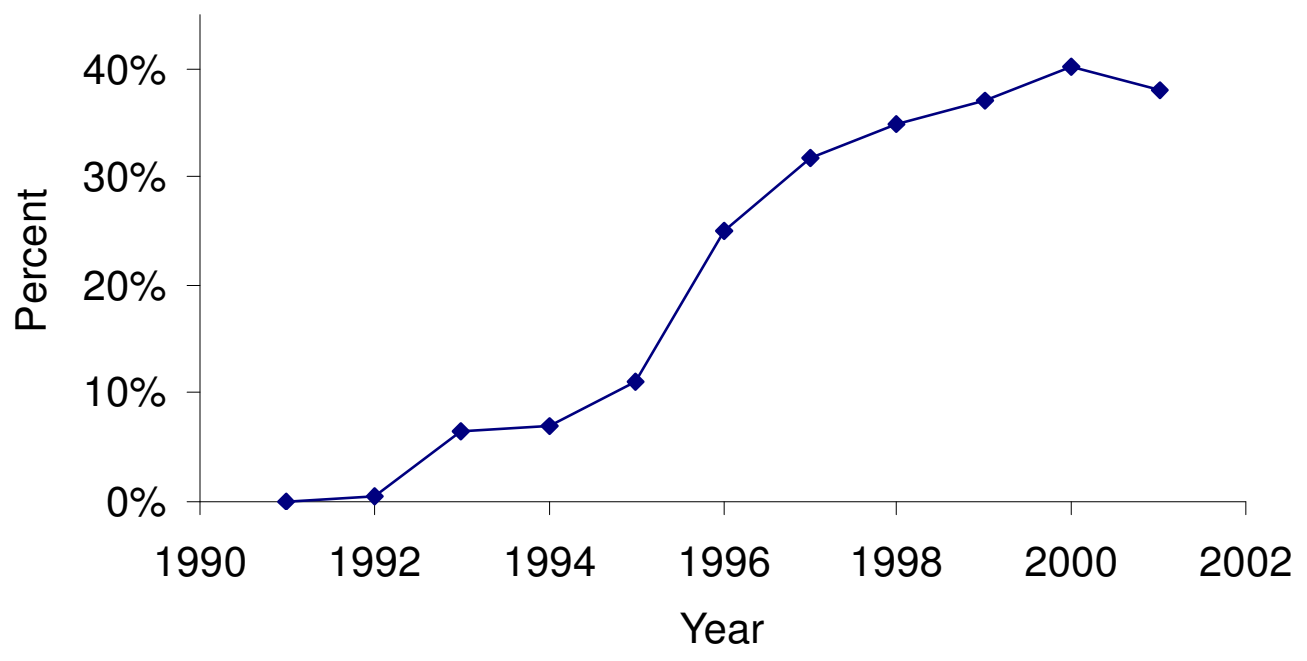

Source: The National Summary of State Medicaid Managed Care Programs, CMS 
Figure 5

Spending and Prescriptions for Cholesterol Lowering Drugs

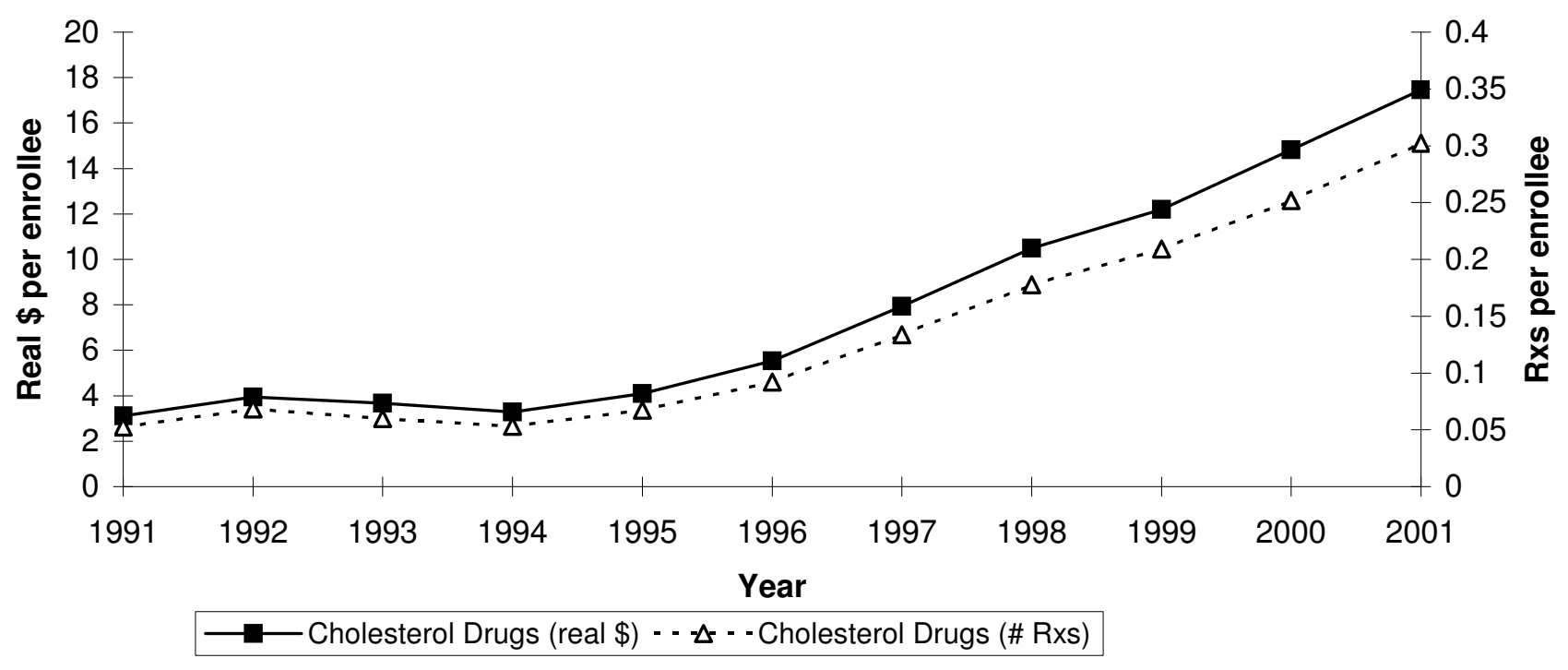

Source: CMS Medicaid Drug Rebate Program 
Table 1: Descriptive Statistics

$(\mathrm{N}=495)$

\begin{tabular}{|l|r|r|r|c|}
\hline \multicolumn{1}{|c|}{ Variable } & \multicolumn{1}{c|}{ Mean } & Std. Dev. & Min & \multicolumn{1}{c|}{ Max } \\
\hline Suicide Deaths, ages 10-19 & 41.23 & 38.45 & 1 & \multicolumn{1}{c|}{234} \\
Suicide Deaths, ages 20 and over & 570.47 & 605.21 & 51 & \multicolumn{1}{c|}{3636} \\
Violent Offenses & 33269.87 & 51940.93 & 415 & 345624 \\
Property Offenses & 229904.40 & 279736.50 & 14171 & 1726391 \\
Juvenile Violent Arrests & 2396.42 & 3854.57 & 0 & 22068 \\
Juvenile Property Arrests & 12200.61 & 14080.99 & 14 & 89900 \\
Unintentional Injury Death, All Types & 163.82 & 155.98 & 8 & 852 \\
Unintentional Injury Death, Drowning & 14.52 & 15.56 & 0 & 93 \\
Unintentional Injury Death, Falls & 2.40 & 2.74 & 0 & 17 \\
Unintentional Injury Death, Burns & 7.15 & 7.30 & 0 & 42 \\
Medicaid Eligibility Threshold & 145.34 & 68.80 & 13 & 400 \\
Medicaid Managed Care (\% enrollees in managed care) & 23.93 & 37.37 & 0 & 100 \\
Medicaid Antidepressants, new drugs (real \$ per enrollee) & 23.22 & 19.48 & 0.48 & 124.98 \\
Medicaid Antidepressants, old drugs (real \$ per enrollee) & 3.35 & 1.75 & 0.22 & 9.43 \\
Medicaid Stimulants (real \$ per enrollee) & 3.33 & 2.75 & 0.11 & 19.31 \\
Medicaid Antidepressants, new drugs (Rxs per enrollee) & 0.40 & 0.33 & 0 & 2 \\
Medicaid Antidepressants, old drugs (Rxs per enrollee) & 0.32 & 0.14 & 0 & 1 \\
Medicaid Stimulants (Rxs per enrollee) & 0.11 & 0.08 & 0 & 0 \\
Female Labor Force Participation (\%) & 60.63 & 4.52 & 44 & 71 \\
Real Income per capita (in \$100s) & 150.94 & 23.81 & 101 & 237 \\
Unemployment (\%) & 5.08 & 1.51 & 2 & 11 \\
College gradutes (\%) & 23.10 & 4.61 & 11 & 39 \\
Population in Rural Counties (\%) & 29.78 & 14.91 & 5 & 67 \\
\hline
\end{tabular}


Table 2

Effects of Medicaid Policies on Suicide Counts

\begin{tabular}{|c|c|c|c|c|}
\hline & All Ages & Age 10-19 & Age $20+$ & All Ages \\
\hline Medicaid Eligibility Threshold & $\begin{array}{l}0.00003 \\
(0.50)\end{array}$ & $\begin{array}{l}-0.001 \\
(-2.260)\end{array}$ & $\begin{array}{l}0.0001 \\
(1.30)\end{array}$ & $\begin{array}{l}0.00004 \\
(0.52)\end{array}$ \\
\hline Medicaid Managed Care Rate & $\begin{array}{l}0.0001 \\
(0.53)\end{array}$ & $\begin{array}{l}-0.0001 \\
(-0.230)\end{array}$ & $\begin{array}{l}0.0001 \\
(0.59)\end{array}$ & $\begin{array}{l}0.0002 \\
(1.32)\end{array}$ \\
\hline Depression New Drugs \$ Per Enrollee & $\begin{array}{r}0.001 \\
(1.69)\end{array}$ & $\begin{array}{l}0.005 \\
(2.85)\end{array}$ & $\begin{array}{l}0.0005 \\
(0.96)\end{array}$ & \\
\hline Depression Old Drugs \$ Per Enrollee & $\begin{array}{l}-0.012 \\
(-3.12)\end{array}$ & $\begin{array}{l}-0.021 \\
(-1.54)\end{array}$ & $\begin{array}{l}-0.011 \\
(-2.82)\end{array}$ & \\
\hline $\begin{array}{l}\text { Cholesterol Lowering Drugs \$ Per } \\
\text { Enrollee }\end{array}$ & & & & $\begin{array}{l}0.0001 \\
(0.11)\end{array}$ \\
\hline Female Labor Force Participation (\%) & $\begin{array}{c}0.003 \\
(1.19)\end{array}$ & $\begin{array}{l}-0.018 \\
(-2.74)\end{array}$ & $\begin{array}{r}0.005 \\
(1.80)\end{array}$ & $\begin{array}{r}0.002 \\
(0.94)\end{array}$ \\
\hline Real Income & $\begin{array}{l}-0.006 \\
(-4.80)\end{array}$ & $\begin{array}{r}0.003 \\
(0.70)\end{array}$ & $\begin{array}{l}-0.007 \\
(-5.21)\end{array}$ & $\begin{array}{l}-0.006 \\
(-4.78)\end{array}$ \\
\hline Unemployment (\%) & $\begin{array}{l}0.004 \\
(0.72)\end{array}$ & $\begin{array}{c}0.013 \\
(0.830)\end{array}$ & $\begin{array}{c}0.003 \\
(0.48)\end{array}$ & $\begin{array}{c}0.004 \\
(0.87)\end{array}$ \\
\hline College Graduates (\%) & $\begin{array}{c}-0.003 \\
(-1.47)\end{array}$ & $\begin{array}{c}-0.010 \\
(-1.51)\end{array}$ & $\begin{array}{c}-0.003 \\
(-1.18)\end{array}$ & $\begin{array}{c}-0.003 \\
(-1.36)\end{array}$ \\
\hline Population in Rural Counties (\%) & $\begin{array}{c}-0.054 \\
(-1.35)\end{array}$ & $\begin{array}{c}0.100 \\
(0.76)\end{array}$ & $\begin{array}{c}-0.064 \\
(-1.55)\end{array}$ & $\begin{array}{c}-0.052 \\
(-1.31)\end{array}$ \\
\hline $\begin{array}{l}\mathrm{N} \\
\text { Pseudo R-squared } \\
\text { Log Pseudolikelihood }\end{array}$ & $\begin{array}{c}495 \\
0.786 \\
-2198.10\end{array}$ & $\begin{array}{c}495 \\
0.422 \\
-1482.42\end{array}$ & $\begin{array}{l}495 \\
0.7753 \\
-2186.88\end{array}$ & $\begin{array}{c}494 \\
0.7852 \\
-2198.24\end{array}$ \\
\hline
\end{tabular}

Coefficient and Z-statistics (in parenthesis). Small coefficient $(b<0.01)$ can be interpreted as a semi-elasticity. All models include state and year fixed effects and state*trend interactions. 
Table 3

Effects of Medicaid Policies on Criminal Offenses and Juvenile Arrests

\begin{tabular}{|c|c|c|c|c|c|c|}
\hline & $\begin{array}{l}\text { Violent } \\
\text { Offenses }\end{array}$ & $\begin{array}{l}\text { Property } \\
\text { Offenses }\end{array}$ & $\begin{array}{l}\text { Violent } \\
\text { Offenses }\end{array}$ & $\begin{array}{l}\text { Property } \\
\text { Offenses }\end{array}$ & $\begin{array}{c}\text { Juvenile } \\
\text { Violent } \\
\text { Arrests }\end{array}$ & $\begin{array}{c}\text { Juvenile } \\
\text { Property } \\
\text { Arrests }\end{array}$ \\
\hline Medicaid Eligibility Threshold & $\begin{array}{c}0.000003 \\
(0.03)\end{array}$ & $\begin{array}{l}0.0002 \\
(1.47)\end{array}$ & $\begin{array}{c}0.00003 \\
(0.26)\end{array}$ & $\begin{array}{l}0.0002 \\
(1.61)\end{array}$ & $\begin{array}{l}0.0004 \\
(1.72)\end{array}$ & $\begin{array}{c}0.0003 \\
(1.91)\end{array}$ \\
\hline Medicaid Managed Care Rate & $\begin{array}{l}0.0001 \\
(0.83)\end{array}$ & $\begin{array}{l}0.0002 \\
(1.32)\end{array}$ & $\begin{array}{l}0.0002 \\
(1.11)\end{array}$ & $\begin{array}{l}0.0002 \\
(1.71)\end{array}$ & $\begin{array}{l}0.00003 \\
(0.08)\end{array}$ & $\begin{array}{l}0.0003 \\
(0.75)\end{array}$ \\
\hline Depression New Drugs \$ Per Enrollee & $\begin{array}{l}0.0003 \\
(0.42)\end{array}$ & $\begin{array}{l}0.0003 \\
(0.70)\end{array}$ & & & & \\
\hline Depression Old Drugs \$ Per Enrollee & $\begin{array}{c}-0.014 \\
(-2.78)\end{array}$ & $\begin{array}{c}-0.010 \\
(-2.38)\end{array}$ & & & & \\
\hline Stimulants \$ Per Enrollee & & & $\begin{array}{c}-0.008 \\
(-2.91)\end{array}$ & $\begin{array}{c}-0.004 \\
(-2.48)\end{array}$ & $\begin{array}{l}-0.002 \\
(-0.44)\end{array}$ & $\begin{array}{l}0.003 \\
(0.60)\end{array}$ \\
\hline Female Labor Force Participation (\%) & $\begin{array}{c}-0.001 \\
(-0.44)\end{array}$ & $\begin{array}{l}-0.005 \\
(-2.16)\end{array}$ & $\begin{array}{c}-0.002 \\
(-0.69)\end{array}$ & $\begin{array}{l}-0.005 \\
(-2.34)\end{array}$ & $\begin{array}{r}0.009 \\
(1.31)\end{array}$ & $\begin{array}{c}0.011 \\
(1.60)\end{array}$ \\
\hline Real Income & $\begin{array}{l}0.0002 \\
(0.15)\end{array}$ & $\begin{array}{c}0.001 \\
(0.86)\end{array}$ & $\begin{array}{l}0.0001 \\
(0.04)\end{array}$ & $\begin{array}{r}0.001 \\
(0.78)\end{array}$ & $\begin{array}{l}0.006 \\
(2.20)\end{array}$ & $\begin{array}{r}0.010 \\
(3.91)\end{array}$ \\
\hline Unemployment (\%) & $\begin{array}{c}0.007 \\
(1.07)\end{array}$ & $\begin{array}{c}0.014 \\
(2.39)\end{array}$ & $\begin{array}{c}0.008 \\
(1.15)\end{array}$ & $\begin{array}{c}0.014 \\
(2.39)\end{array}$ & $\begin{array}{c}-0.024 \\
(-1.70)\end{array}$ & $\begin{array}{c}-0.006 \\
(-0.50)\end{array}$ \\
\hline College Graduate (\%) & $\begin{array}{c}-0.003 \\
(-1.18)\end{array}$ & $\begin{array}{c}0.001 \\
(0.61)\end{array}$ & $\begin{array}{c}-0.002 \\
(-0.83)\end{array}$ & $\begin{array}{c}0.002 \\
(0.88)\end{array}$ & $\begin{array}{c}0.008 \\
(1.57)\end{array}$ & $\begin{array}{c}0.006 \\
(1.25)\end{array}$ \\
\hline Population in Rural Counties (\%) & $\begin{array}{c}-0.129 \\
(-2.69)\end{array}$ & $\begin{array}{c}-0.097 \\
(-2.41)\end{array}$ & $\begin{array}{c}-0.119 \\
(-2.50)\end{array}$ & $\begin{array}{c}-0.090 \\
(-2.23)\end{array}$ & $\begin{array}{c}0.234 \\
(2.77)\end{array}$ & $\begin{array}{c}0.212 \\
(2.44)\end{array}$ \\
\hline $\begin{array}{l}\text { N } \\
\text { Pseudo R-squared } \\
\text { Log pseudolikelihood }\end{array}$ & $\begin{array}{r}488 \\
0.988 \\
-17131.3\end{array}$ & $\begin{array}{r}492 \\
0.979 \\
-73516.1\end{array}$ & $\begin{array}{r}487 \\
0.988 \\
-17243.4\end{array}$ & $\begin{array}{r}491.000 \\
0.979 \\
-74132.7\end{array}$ & $\begin{array}{c}472 \\
0.9419 \\
-7704.08\end{array}$ & $\begin{array}{c}472 \\
0.9355 \\
-31794.9\end{array}$ \\
\hline
\end{tabular}

Coefficient and Z-statistics (in parenthesis). Small coefficients $(b<0.01)$ can be interpreted as a semi-elasticity. All models include state and year fixed effects and state*trend interactions. 
Table 4

Effects of Medicaid Policies on Fatal Unintentional Injuries

\begin{tabular}{|l|c|c|c|c|}
\hline & $\begin{array}{c}\text { All Injury } \\
\text { Types }\end{array}$ & Drowning & Falls & Burn \\
\hline Medicaid Eligibility Threshold & 0.0003 & 0.001 & -0.001 & -0.0003 \\
& $(1.91)$ & $(1.07)$ & $(-1.19)$ & $(-0.38)$ \\
Medicaid Managed Care Rate & 0.0003 & 0.0003 & -0.003 & 0.002 \\
Stimulants \$ Per Enrollee & $(1.11)$ & $(0.41)$ & $(-1.55)$ & $(1.70)$ \\
& -0.004 & 0.007 & -0.0175 & -0.018 \\
Female Labor Force Participation & $(-1.09)$ & $(0.67)$ & $(-0.63)$ & $(-0.86)$ \\
(\%) & -0.008 & 0.003 & 0.014 & -0.004 \\
Real Income & $(-2.06)$ & $(0.22)$ & $(0.57)$ & $(-0.16)$ \\
Unemployment (\%) & 0.001 & -0.012 & 0.007 & -0.012 \\
& $(0.26)$ & $(-1.90)$ & $(0.59)$ & $(-1.03)$ \\
College Graduate (\%) & -0.006 & 0.007 & -0.068 & 0.005 \\
Population in Rural Counties $(\%)$ & $(-0.69)$ & $(0.25)$ & $(-1.20)$ & $(0.11)$ \\
N & -0.005 & 0.013 & 0.013 & 0.003 \\
Pseudo R-squared & $(-1.20)$ & $(1.10)$ & $(0.53)$ & $(0.15)$ \\
Log pseudolikelihood & 0.106 & 0.016 & -0.312 & -0.270 \\
Coeficist & $(1.54)$ & $(0.06)$ & $(-0.67)$ & $(-0.74)$ \\
& 494 & 494 & 494 & 494 \\
\end{tabular}

Coefficient and Z-statistics (in parenthesis). Small coefficients $(b<0.01)$ can be interpreted as a semi-elasticity. All models include state and year fixed effects and state*trend interactions. 
Table 5

Effects of Number of Prescriptions on Outcomes

\begin{tabular}{|c|c|c|c|c|}
\hline Panel A & Suicides ages 10-19 & $\begin{array}{c}\text { Suicides } \\
\text { ages } 20 \text { and up }\end{array}$ & Violent Offenses & Property Offenses \\
\hline Medicaid Eligibility Threshold & $\begin{array}{c}-0.001 \\
(-2.21)\end{array}$ & $\begin{array}{l}0.0001 \\
(1.20)\end{array}$ & $\begin{array}{l}0.00001 \\
(0.07)\end{array}$ & $\begin{array}{c}0.0002 \\
(1.49)\end{array}$ \\
\hline Medicaid Managed Care Rate & $\begin{array}{l}-0.0001 \\
(-0.15)\end{array}$ & $\begin{array}{l}0.0001 \\
(0.94)\end{array}$ & $\begin{array}{l}0.0002 \\
(1.20)\end{array}$ & $\begin{array}{l}0.0002 \\
(1.67)\end{array}$ \\
\hline Depression New Drugs Rx Per Enrollee & $\begin{array}{l}0.250 \\
(2.02)\end{array}$ & $\begin{array}{l}0.063 \\
(1.70)\end{array}$ & $\begin{array}{l}-0.018 \\
(-0.37)\end{array}$ & $\begin{array}{l}-0.001 \\
(-0.03)\end{array}$ \\
\hline Depression Old Drugs Rx Per Enrollee & $\begin{array}{l}-0.225 \\
(-1.16)\end{array}$ & $\begin{array}{l}-0.141 \\
(-2.43)\end{array}$ & $\begin{array}{l}-0.083 \\
(-1.14)\end{array}$ & $\begin{array}{r}-0.069 \\
(-1.11)\end{array}$ \\
\hline Panel B & Violent Offenses & Property Offenses & $\begin{array}{c}\text { Juvenile Violent } \\
\text { Arrests }\end{array}$ & $\begin{array}{c}\text { Juvenile Property } \\
\text { Arrests }\end{array}$ \\
\hline Medicaid Eligibility Threshold & $\begin{array}{l}0.00001 \\
(0.14)\end{array}$ & $\begin{array}{l}0.0002 \\
(1.48)\end{array}$ & $\begin{array}{l}0.0004 \\
(1.71)\end{array}$ & $\begin{array}{l}0.0003 \\
(1.88)\end{array}$ \\
\hline Medicaid Managed Care Rate & $\begin{array}{l}0.0002 \\
(1.31)\end{array}$ & $\begin{array}{l}0.0002 \\
(2.06)\end{array}$ & $\begin{array}{l}0.0001 \\
(0.18)\end{array}$ & $\begin{array}{l}0.0003 \\
(0.88)\end{array}$ \\
\hline Stimulants Rx Per Enrollee & $\begin{array}{l}-0.146 \\
(-1.81)\end{array}$ & $\begin{array}{l}0.011 \\
(0.15)\end{array}$ & $\begin{array}{c}0.029 \\
(0.18)\end{array}$ & $\begin{array}{r}0.291 \\
(1.66)\end{array}$ \\
\hline Panel C & All Injury Types & Drowning & Falls & Burn \\
\hline Medicaid Eligibility Threshold & $\begin{array}{l}0.0003 \\
(1.86)\end{array}$ & $\begin{array}{l}0.0005 \\
(1.08)\end{array}$ & $\begin{array}{l}-0.001 \\
(-1.23)\end{array}$ & $\begin{array}{l}-0.0004 \\
(-0.41)\end{array}$ \\
\hline Medicaid Managed Care Rate & $\begin{array}{l}0.0004 \\
(1.27)\end{array}$ & $\begin{array}{l}0.0003 \\
(0.39)\end{array}$ & $\begin{array}{l}-0.003 \\
(-1.49)\end{array}$ & $\begin{array}{l}0.003 \\
(1.85)\end{array}$ \\
\hline Stimulants Rx Per Enrollee & $\begin{array}{l}0.063 \\
(0.42)\end{array}$ & $\begin{array}{l}0.147 \\
(0.43)\end{array}$ & $\begin{array}{c}-0.214 \\
(-0.27)\end{array}$ & $\begin{array}{l}0.127 \\
(0.17)\end{array}$ \\
\hline
\end{tabular}

Coefficient and Z-statistics (in parenthesis). Small coefficients $(b<0.01)$ can be interpreted as a semi-elasticity. All models include state characteristics, state and year fixed effects and state*trend interactions. 